\title{
BUILDING CAPACITY IN ALBANIA THROUGH COORDINATED RESEARCH ACTIVITIES IN NUCLEAR SECURITY
}

\author{
Dritan Prifti $^{1 *}$, Kozeta Tushe ${ }^{1}$, Charles Massey ${ }^{2}$, Elida Bylyku${ }^{1}$, Brunilda Daci ${ }^{1}$ \\ I*Institute of Applied Nuclear Physics, Street "Thoma Filipeu” Qesarakë, P.O Box 85, Tirana, Albania; \\ ${ }^{2}$ International Atomic EnergyAgency, Vienna International Centre, PO Box 100, 1400 Vienna, Austria; \\ "Corresponding Author Dritan Prifti, e-mail: dritan.prifti@unitir.edu.al;
}

Received October 2020; Accepted November 2020; Published January 2021;

DOI: https://doi.org/10.31407/ijees11.105

\begin{abstract}
The Institute of Applied Nuclear Physics (IANP) is established in 1970 and is the main user of the radioactive sources in Albania. IANP is a focal point and the main user and provider of nuclear and nuclear related techniques in the country and conducts research, applications, education and expert training in this field. In July 2016 IANP joined the Coordinated Research Project (CRP) J02005 titled "Improved Assessment of Initial Alarms from Radiation Detection Instruments" and in August 2018 joined the CRP J02012 titled "Advancing Radiation Detection Equipment for Detecting Nuclear and Other Radioactive Material out of Regulatory Control" in collaboration with General Custom Directorate (GCD). Participation in the CRP J02005 and the knowledge gained in understanding more the radiation detection system operations, has been a great support in improvements on how systems can be more sustainable. In the CRP J02012, the work has been focused in research experiments with different portable radiation detection instruments that are disposable at IANP. In collaboration with Department of Physics in the Faculty of Natural Sciences are conducted research experiments involving different age, weight and sex of people (students and Institute of Applied Nuclear Physics personnel). The research experiments are performed in different weather conditions (winter/ summer) classroom and field conditions for determining optimal equipment specifications. In August 2019 IANP joined the CRP J02014 titled "Advancing Maintenance, Repair and Calibration of Radiation Detection Equipment". Participation in the above CRPs provided opportunity to expand professional experience and to strengthen the cooperation between IANP and the GCD.
\end{abstract}

Keywords: research experiments, commodity, coordinate research project, radiation detection 